Journal of the Scholarship of Teaching and Learning, Vol. 19, No. 3, June 2019, pp.79-90.

doi: 10.14434/josotl.v19i2.23970

\title{
"There is no escaping it": Graduate Student Conceptions of Environment and their Implications for Learning Motivation and Public Health Curricula
}

\author{
Katherine L. Cheesman \\ Indiana University \\ Emily Q. Ahonen \\ Indiana University \\ eqahonen@iu.edu
}

\begin{abstract}
This manuscript stems from observations the authors made while teaching an environmental health course, which is part of a Master of Public Health (MPH) degree. Observations of student attitudes and patterns in course feedback prompted questions about how to pique interest in the course content. There has been considerable research attention given to the role of motivation in student learning and performance outcomes. How student motivation is generated, sustained, and impacted by educational curricula has inspired the development and revision of different theoretical models designed to explain these relationships. But the literature on adult professional learner motivation is less robust, which is important because adult learners enter classroom settings with academic and experiential knowledge. All of the existing theories of learning motivation build upon the assumed premise that students perceive the subject matter in a certain way. For adult, professional degree-seeking students in any field, however, the motivation to learn is contingent upon their preexisting conceptions of the course material - its value, relevance, and application to future career goals. Therefore, better understanding of this basis for learning in adults is important. We explore the ways in which entering MPH students conceive of one component of public bealth education in order to structure the course to maximize student motivation. The implications of our findings for educators in other professions are discussed.
\end{abstract}

Key words: student motivation; Transformative Learning Theory; public health; adult learning; professional education and training

\section{Introduction}

This manuscript stems from questions about adult motivation to learn prompted by observations the authors made while teaching an environmental health course which is part of a Master of Public Health $(\mathrm{MPH})$ degree. A MPH is the professional practice degree for those people whose focus is protecting and promoting the health status of the population. Public health workers hail from many disciplines of origin, and the MPH degree aims to build applied scientific skills and channel disciplinary worldviews toward assessment, planning, monitoring, coalition and partnership development, management, leadership, communication, policy development, and cultural humility in service of the prevention of disease and injury, and the prolonging of life (APHA, 2017; WHO, 2017). Environmental public health - a core area of public health - focuses on the relationships between the environment and human health; many diseases and injuries are initiated, promoted, sustained, or stimulated by environmental factors. Conversely, environments may also promote better states of health. 


\section{Course context and overview}

Students in MPH programs generally choose a concentration in one of the core areas of public health (i.e., Environmental Health, Epidemiology, Health Policy \& Management, or Social \& Behavioral Sciences), but must still be exposed to core principles of each area. The course addressed here serves that core function in our program. It is in many senses a survey course, structured in three sections: (1) environmental determinants of population health status, (2) fundamental assessment tools, and (3) strategies for solving environmental health problems and pursuing health equity. Students learn to consider health-relevant components of several types of environments: The ambient environment (i.e., air, water, soil), the built environment (e.g., housing and other buildings, physical infrastructure such as sidewalks and roads), the occupational environment (i.e., places people work), and the social aspects of environment present in any of the former ones. The course also addresses the fact that much of prevention in environmental health must curtail human activity which pollutes the environments we occupy. The sections of the course are woven together by a multi-part assignment in which students choose an environmental health concern, describe and analyze it, and propose ways to address the problem using disciplinary tools; this assignment is intended both to build systematic analysis skills as well as promote a systems view of environmental public health.

Regardless of the disciplinary concentration a student chooses, understanding the relationships between the environment and the health of populations is fundamental to addressing any public health concern. Across specific course learning objectives, the major instructional goal is that students come to see the necessity of examining the contribution of environments in any public health concern, and learn systematic processes for doing so. This goal notwithstanding, over the course of several semesters, the instructor observed trends in the ways students interacted with, sought to understand the material, and responded to the course:

(1) Seemingly narrow perception of the environmental health discipline;

(2) Apparent apathy toward environmental components of the broader public health field;

(3) Consistently lower "relevance to discipline" and "stimulated to learn more" than other scores received in end-of-term course evaluation feedback.

These observations prompted the study described here.

\section{Student motivation \& learning}

A review of the literature indicates a considerable interest amongst the scientific community regarding the role of motivation in student learning and performance outcomes. How student motivation is generated, sustained, and impacted by educational curricula has inspired the development and revision of different theoretical models designed to explain these relationships.

Early models of academic achievement and motivation characterized student goals as being either (1) mastery or (2) performance oriented (Ames \& Archer, 1988; Dweck, 1986). Others posited that motivation could be calculated as a product of motive, expectancy, and incentive (Atkinson \& Feather, 1966). More recent revisions—-such as those to Achievement Motivation Theory-however, have proposed a third goal orientation termed "academic alienation" (Archer, 1994). Students who approach learning with an academic alienation mentality do so with the notion that their interests lie outside of the classroom. Consequently, these students are not motivated to master the material nor demonstrate their abilities. Rather, alienated students aim to fulfill course requirements with minimal effort, concentrating their ambition elsewhere (Archer, 1994).

Another more recent and widely employed explanation of student motivation stems from SelfDetermination Theory (SDT) (Ryan \& Deci, 2000). According to SDT, student behavior is determined

Journal of the Scholarship of Teaching and Learning, Vol. 19, No. 3, June 2019. josotl.indiana.edu 
by the type of motivation s/he experiences relevant to the given behavior. Ideally, students are intrinsically motivated to be engaged with their coursework, driven by an internal source of inherent interest in the materials/activities. More commonly, however, students are motivated extrinsically, driven to engage in behaviors only by external demands (e.g., punishment, reward). It is also possible for students to experience no motivation at all (i.e., amotivation).

Despite the substantial body of research supporting the conceptualization/application of the aforementioned theories, it is pertinent to note that the majority of literature on student motivation has been developed around the experiences of child, adolescent, and undergraduate learners. Research on the role of motivation in student learning and performance outcomes amongst adult learners is far less robust, but nonetheless deserving of equal consideration. This may be especially true given the combination of shifts to a globalized, service-based economy, rapid technological change, and demographic imperatives (i.e., retirement of Baby Boom generation) which prompt adults to seek new or refined perspectives and skills.

\section{Adult learners \& academic motivation}

Unlike undergraduate student populations, individuals pursuing an $\mathrm{MPH}$ are adult learners who already have a bachelor's degree and are eligible for employment. Further education is sought, then, not to simply "get a job", but to increase mobility within one's current field or to enhance one's qualifications toward a higher level of career attainment (Rothes, Lemos, \& Gonçalves, 2014). The term andragogy, coined by Alexander Kapp in 1833, is used to refer to the education of adult learners and its unique demands. Andragogy has since been popularized by Malcolm Knowles, whose research characterizes adult learners as self-directed and task-oriented (Knowles, 1984; Knowles, Holton, \& Swanson, 2015).

The literature on andragogy suggests that adult learners differ from their undergraduate counterparts in their motivation to learn: what motivates them, why, and how. Unlike undergraduates, research indicates that adult learners adjust their decision-making processes to navigate between academic and professional relevance (Hegarty, 2011). Instead of approaching learning with the singular goal of mastering course content, these students also must take into account whether or not the material at hand will be applicable to their current and/or desired field of employment. Knowles (1973) postulates that adult learners approach coursework based on its "immediacy of application", prioritizing the materials that they deem relevant to their own careers-current or anticipated. These findings call into question the longstanding assumption that adult learners are innately "volunteers for learning", suggesting that their motives may instead be rooted extrinsically (e.g., higher pay, job promotion) (Carre, 2000; Rothes et al., 2014).

Additionally, the literature suggests that adult learners are largely influenced by their prior experiences to a much greater degree than their adolescent (or even undergraduate) counterparts. Transformative Learning Theory posits that learning occurs only within an individual's "frame of reference", defined by Cranton (2000) as "complex webs of assumptions, expectations, values, and beliefs that act as a filter or screen through which we view ourselves and the world" (Mezirow, 1997; Mezirow \& Taylor, 2009). Adult learners are especially prone to approach new information through preconceived knowledge. Their motivation to learn, then, is largely contingent on what they believe they already know. Applying this theory to the present population of interest would suggest that public health students enter into the core environmental public health course with a preexisting idea of "what environmental public health is"-and by that subjective definition-whether or not the course content is applicable to their professional goals.

The tendency of adult learners to "filter out" information that they (1) already know or (2) deem irrelevant, however, is inherently problematic in that students could potentially be approaching

Journal of the Scholarship of Teaching and Learning, Vol. 19, No. 3, June 2019.

josotl.indiana.edu 
coursework with an erroneous foundation of understanding. The literature categorizes these preconceived ideas as either "misconceptions" or "alternative conceptions". Misconceptions are defined as "misunderstandings which have probably occurred during or as a result of recent instruction" (Griffiths, Thomey, Cooke, \& Normore, 1988). Alternative conceptions are more firmly rooted, having developed and endured over a longer period of time (Griffiths et al., 1988; Zoller, 1996). In theory, alternative conceptions may be most relevant to adult learners whose knowledge accumulated through professional experience does not necessarily reflect the learning objectives of a formalized academic curriculum.

In summary, all of the existing theories of learning motivation build upon the assumed premise that students perceive the subject matter in a certain way. For adult, professional degree-seeking students in any field, however, the motivation to learn is contingent upon their preexisting conceptions of the course material - its value, relevance, and application to future career goals. In order to address the attitudes and performance of our students, then, we needed to know how they are perceiving the subject matter. To understand how our students defined "environment", our data collection method was rather straightforward: we simply asked them.

\section{Methods}

\section{Participants}

All students who enrolled in the environmental health core course between fall semester 2015 and spring 2017 were potential participants. Table 1 shows the variety of undergraduate studies that students reported upon entry to the Master of Public Health or Public Health Certificate in years coinciding with our data collection. At the time of entry, fully $90 \%$ of those students opted for a concentration other than Environmental Health Science (10\%). Most entering students (52\%) held Bachelor of Science undergraduate degrees (data not shown). Natural sciences and pre-health, health sciences, or nursing majors predominated. Overall, about $15 \%$ of entering students also reported having some other post-graduate study (data not shown).

\begin{tabular}{ll}
\hline Table 1. Undergraduate Area of Study for Incoming \\
Certificate Students, 2014-16. \\
\hline Undergraduate Area of Study & Count* \\
Natural Sciences & 77 \\
Social Sciences & 39 \\
Humanities & 22 \\
Education & 3 \\
Engineering & 4 \\
Pre-Health Professions/Health Sciences/Nursing & 54 \\
Pre-Professions/Non-Health & 12 \\
Other/Interdisciplinary & 7 \\
Public Health & 9 \\
Unknown & 3 \\
\hline$*$ Count refers to number of degrees, not number of students; therefore \\
total is greater than the total number of students
\end{tabular}

Journal of the Scholarship of Teaching and Learning, Vol. 19, No. 3, June 2019. josotl.indiana.edu 


\section{Data collection}

As a first class activity, students described what they understood to be the subject of the course through the following untimed writing prompt:

How would you define "environment"? Keep in mind that we are not looking for any particular answer or a certain "right" answer. In fact, we each likely have a slightly different definition for this word, and that's okay. Tell us about your definition.

To prompt participation, the assignment was graded on a completion/non-completion basis.

\section{Analyses}

Data were transferred verbatim to Excel spreadsheets for analyses, which followed the general inductive analytic approach described by Thomas (2006), useful here because we aimed to work toward a model to understand student motivation in future research. Our procedure was iterative, involving multiple phases of code development, application to data, discussion, and refinement of our code list.

When data collection was finalized, both authors performed an initial read-through of all data and KLC developed an initial code list which contained general and sub-codes and examples from the data for each. The initial code list contained descriptive codes, where an analyst-developed label is applied to pieces of data, and causal codes, where the code denotes that the data suggest one thing influences another (e.g., the code HUMAN INFLUENCE ON ENVIRONMENT labeled pieces of data where students indicated that human actions impacted environments). After discussion toward achieving mutual understanding of this preliminary code list, each analyst independently used it to apply the codes to a sub-set of the data. They then compared their application of the codes to the data sub-set. In cases of disagreement, discussion to consensus led to one of three outcomes: (1) revision of the code and its definition; (2) development of a new code; or (3) revision of the code applied to the segment of text. In addition, this phase served to assess the structure of the code book. For instance, while simultaneous coding (application of more than one code to the same section of text; Miles, Huberman \& Saldaña, 2014) was allowed throughout analyses, if too many codes were applied to any given section of text, making interpretation untenable, then this might signal that the code book needed to be revisited (Miles, Huberman \& Saldaña, 2014).

Both analysts then used the revised code book to apply codes independently to all data. After this phase, another round of discussion identified the need for one additional code, and for modification of another. Following this discussion, both coders re-coded all data using the finalized code book, which contained descriptive researcher-developed, causal, and in vivo (i.e., derived from the actual words used by respondents) codes. The results of independent coding were compared; remaining differences in coding were resolved through discussion to yield a final coded data set.

Next, one analyst (KLC) developed pattern codes by clustering together codes which had something in common, considering the meaning they had as a group. We then used brief narrative descriptions to describe the relationships among the codes and the larger patterns we were seeing. Through discussion, we assessed these clusters for what we believed held them together; sometimes, this cluster highlighted a larger theme or category which deepened our analyses as we wrote to explain themes we saw to each other (Miles, Huberman \& Saldaña, 2014). Throughout, both analysts used analytic memoing as they applied codes to track ideas and insights. For instance, after the first round of applying codes to all data, we noted that two codes, FIXED and MULTIPLE ENVIRONMENTS, often co-occurred, leading to a brief discussion about what might be behind that. In another example, 
we noted that students very frequently began their answers with a very broad, vague topic sentence, and then further specified their answers. The memoing process allowed us to track possible insights and points for discussion.

\section{Results}

Our findings are organized into two sections. First, we describe the overall content and tone which characterized student responses: what they believed environment was, and how they described it. Next, we present two major themes which emerged from our analyses which reflect the ways in which students positioned themselves with regard to the environments they described. Throughout this section, code names are indicated in ALL CAPITAL LETTERS. Single quotes indicate a generality observed by researchers; double quotes indicate actual words or phrases used by students.

\section{Student conceptions of environment}

Many student responses were characterized by an umbrella/topic sentence, which was quite VAGUE or ALL-ENCOMPASSING. Vague responses were those that did not identify specific components of environment (i.e., "the world around us") or failed to elaborate on a broad concept (i.e., "external factors to an individual"). All-encompassing responses identified large, overlapping components of the environment (i.e., "the physical, biological, chemical, social and psychological surroundings and conditions"), commonly prefaced by "including..." or followed with "etc....".

All-encompassing topic sentences were usually followed by additional clarification which further specified components of environments and their characteristics. Many responses characterized either (1) the environment itself or (2) its contents/composition as having a spatial/tangible PHYSICAL existence. When applied to the environment, this idea was usually associated with terms like "space" or "surroundings" or "physical", and the "things" that occupied the physical space. For some students, this physical space was geographically stationary. Recurrent terms such as "place", "area", "space", and "location" were used in these responses to establish the environment as a concept anchored to a FIXED location. In keeping with the idea of a physical location, some student responses indicated the existence of more than one environment-often differentiated in terms of climate, geography, or other characteristics of place (e.g., desert vs. rainforest, urban vs. rural). Other responses which identified MULTIPLE ENVIRONMENTS defined environments based on scope (e.g., microscopic vs. global) or type (e.g., natural vs. man-made).

Presented in contrast to the "physical environment", SOCIAL environment was typically described in two ways: (1) people/friends/family/community are part of environment because they occupy its space or (2) people/friends/family/community represent an interactive component/layer that functions as a part of environment itself. This idea was most frequently used in conjunction with a description of other aspects of environment (e.g., "natural", "man-made") which, in conjunction, made up the larger/general environment. That is, no student responses suggested "environment" was purely social in nature. Another component suggested by students was that, in whole or in part, environment involved some aspect of "nature", coded as TREES AND ROCKS. Commonly cited components of this category were plants, animals, air, water, forests, rocks/geology, and soil. These words were often used as examples of "natural" or "pre-existing" aspects of the environment, presented in contrast to SOCIAL or BUILT components. The latter was most frequently used in conjunction with other codes. Many students presented the built or "man-made" environment as existing in contrast to the "natural" environment. In some instances, the built environment was combined with the natural environment to comprise the "physical" aspects of the environment, juxtaposing these facets with its social/cultural elements. Sometimes, students did not use the term

Journal of the Scholarship of Teaching and Learning, Vol. 19, No. 3, June 2019.

josotl.indiana.edu 
'built environment', but described its parts, such as sidewalks or buildings. Finally, though it was less described than social or built environmental components, OCCUPATIONAL space was mentioned by some students specifically as an environment, or, more frequently, as part of a short list of what an environment is (e.g., places where people "live, work, play").

Finally, a minority of students gave more concise answers which contained language that would typically be affiliated with the natural sciences (e.g., chemistry, biology, geology, ecology). Typically, these responses_coded as SCIENCE_-described the environment as being composed of smaller, physical units (e.g., molecules, cells) or used scientific terminology (e.g., geosphere, biotic/abiotic, organic/inorganic, symbiotic).

Ideally, students beginning a degree in public health would have a basic appreciation of environments delineated in the course: the ambient, built, occupational, and social environments and their overlaps. While there were very few comprehensive answers of that sort, after an initial vague statement, many students did specify some of these environments or provide examples in a list-like manner followed by "etc." or "and other things". An example of a student response with this type of structure is: "Environment is our surroundings. It includes all livings (such as Trees, Animals, Parasites, Viruses, and etc.) and Also Non-livings (Such as Buildings, Factories, Cars, Airplanes, Trains, and etc.)". There are two ways that this finding could be interpreted:

1. Students have a thorough understanding of the various environments and merely listed the examples that came to mind. The "etc." often included in the initial umbrella statement represents a complex breadth of information-known to the students—-that simply did not make its way to the paper.

2. Students have a less-than-thorough understanding of the environmental components they highlight, and merely listed the examples that came to mind. The "etc." represents a complex breadth of information-unknown to the students-that has yet to be learned/understood.

These possibilities are further illuminated by the themes identified, and will be considered more thoroughly in the Discussion section.

\section{Human positionality}

Theme 1: Influence vs. Imminence. A cluster of codes we used to describe human positionality visà-vis environments suggested how they saw the relationship between humans and their environments. Some responses described a reciprocal HUMAN-ENVIRONMENT INTERACTION. These responses recognized the environment's role in "shaping" human health and/or life outcomes. This code was applied to both physical effects (i.e., air pollution, water quality) and behavioral and social factors (i.e., learned health behaviors, socioeconomic status). The more PHILOSOPHICAL posed a relationship between humans and their environment, referring to the Earth as our "home" or a space in which we "thrive". Others defined environment as a component of one's "existence", expounding upon the interconnectedness between humans and their environment.

A more substantial portion of the responses, however, discussed the means by which the environment influences and shapes human life uni-directionally; some responses painted a grim picture of the environment and how devastating/limiting it can be to human life. In the most extreme cases, HUMAN DEPENDENCE ON THE ENVIRONMENT, though very infrequent, characterized the environment as something humans require for survival, indicating not just a relationship, but a dependency. In contrast, reflection about the HUMAN IMPACT ON ENVIRONMENTS or POLLUTION were not intensely present in our data. When pollution was

Journal of the Scholarship of Teaching and Learning, Vol. 19, No. 3, June 2019.

josotl.indiana.edu 
mentioned, it was often as simple as a phrase indicating that human activity can introduce pollution into environments; in general, answers did not indicate an understanding of complex relationships or systems of mutual influence nor interdependence.

Theme 2: Environment as being individually-focused. For many students, understandings of the environment might be described as person-centered or individually-focused. These students placed themselves, "an individual", or even sometimes "an organism" at the center of their framing of environment. In some cases, this sort of definition was fixed, as in: "Environment is the area or condition in which someone lives and operates"; "surroundings and forces that a living organism incurs in a particular place"; or "an organism's environment consists of where it is located, who it is around, and the climate of the area". In other cases, an element of time was included, as students framed environment as whatever was around a person at any moment in time. Unlike large-scale changes (e.g., climate change), these responses illustrated an individual's movement as being accompanied by the environment. These movements were described as occurring over the span of a day (e.g., home environment vs. work environment) or over the lifespan (e.g., childhood home vs. adult residence). That is, environment was still based around the individual, but as the individual moved through space and time, environment went with her. Definitions which referenced this sort of person-centered view included "any setting in which a person may find himself", "the place where the person currently is", and "environment is all around us, there is no escaping it".

The centrality of the individual in some cases included a person's emotional and sometimes cognitive experience of environment. These students described environment as having a "feeling" or "pace". Some of these views were quite abstract, as in: "energies, sounds, textures, colors, and overall presence", "perceived actions, thoughts, or ideas within that area", and "every 'person' is their own environment". In other cases, the emotional aspect was framed as positive or negative, as in environments which are "uncomfortable", "positive", "welcoming", or those which are framed in terms of response to others (e.g., "how friendly or hostile those around you are").

\section{Discussion}

In the Results section, we proposed that the vague topic sentence followed by a list of types or components of environments structure of many student answers suggested either that (1) students had an appropriately broad descriptive sense of environments upon entering the course which they partially summarized, indicated the rest of what they knew with "etc.", or that (2) they had partial understandings, wherein the "etc." symbolized a lack of concrete understanding and/or things yet to be defined. In light of the themes which emerged from our data, we believe the second possibility is the more likely one. If student conceptions of the complex interactions between humans and environments were broader and more nuanced, it is unlikely that the sense that environments 'happen to us' would be strongly present. Likewise, an ideally public-health mindset would not so clearly emphasize the individual, and would instead highlight population-level actions and impacts within environment-human systems. The nature of the question we posed to students, however, is that there are technically no "wrong" answers. Moreover, while we found no glaring patterns in factual incorrectness, our data do suggest that instructors must work to help students systematize and 'complexify' their understanding of (1) environments, (2) the components in them relevant to human health and well-being, and (3) the interactions between human activity and environmental states and conditions.

In contrast to less ambiguous learning concepts (i.e., mortality rates), student definitions of environment are expected to be subjective. A mix-up between "mortality" and "morbidity", for example, would constitute a student "misconception" that could be easily corrected in the classroom environment. Correcting a student's notion that the environment is beyond human influence, 
however, requires an invalidation of his/her learned experiences. These firmly rooted understandings of "truth" uncovered in our data collection are better defined as "alternative conceptions", the remediation of which poses a formidable challenge to student learning (Griffiths et al., 1988).

This challenge has implications for the state of public health. One of the first and most fundamental concepts addressed in public health degree programs are levels of prevention, in which primary or "upstream" prevention (i.e., prevention of a challenge to health before it can manifest in any way, such as through vaccination) is the preferred option. In student responses, we noted an underlying theme of environmental health problems being out of the scope of human influence. Many students characterized the environment as something that determines human outcomes, but failed to discuss the fact that it is just as often human activity which changes environments to be less healthful. This not only means that (1) students may not be making the connection to systems and "upstream" human-created influence on environments (e.g., through pollution), but (2) it also suggests that they are positioning themselves as passive experiencers of environment. If students are to leave the program as active change agents in the service of public health, this perception is a fundamental one to change.

\section{Implications}

In reviewing the demographic makeup of our student body, we have found it to be fairly representative of a "typical" professional program. The majority of our students have already earned undergraduate degrees in the natural sciences and health professions, making them eligible for employment. We know from the literature that these adult learners likely have career-specific motivation for returning to school. And by asking our students how they defined environmental concepts before engaging in the coursework, we have gained better understanding of how they perceive the subject matter. It is now pertinent to discuss how our findings "fit" into the existing theories of learning we previously introduced.

Achievement Motivation Theory would suggest that our students-professional adult learners-may be "alienated" from their coursework (Archer, 1994). If a student vaguely perceives the environment as being "any setting in which a person may find himself', he may not recognize its application to his aspiring career in healthcare policy. Even students without firm professional agendas may fail to see how the environment fits into the broader scope of public health practice, especially if they perceive it as being "fixed" or "imminent". These alternative and/or misconceptions lead students to make inaccurate judgements regarding the material's "immediacy of application" to their professional endeavors (Griffiths et al., 1988; Knowles, 1973). In summary, learning theory would suggest that the disconnect we have observed amongst our students is not unprecedented. The "academic alienation" experienced by our students stems from the tendency of adult learners to only learn what it is they do not already know-even if what they already know is inaccurate.

\section{Relevance to other disciplines}

The challenges associated with educating adult learners are not unique to public health. There are a number of professional programs that operate in a similar manner to public health training. Any discipline that offers advanced credentialing, training, or licensure can expect to attract adult learners-people with some degree of real-life experience that they bring with them into the classroom. In order to better motivate these students, instructors must first acknowledge and address pre-existing conceptions of what students believe they (1) already know, (2) have yet to learn, or (3) what will be applicable to their intended career.

Journal of the Scholarship of Teaching and Learning, Vol. 19, No. 3, June 2019. josotl.indiana.edu 


\section{Future Directions}

Transformative Learning Theory (TLT) (Mezirow, 1997) poses recommendations to educators who seek to meet this challenge in adult education. In order to "transform" the learner's perception of the subject matter, educators must present the concept in the context of his/her own life. Transformative learning also calls for educators to initiate and maintain a classroom environment in which students are free to be critical in their assessment of new knowledge, as well as their existing assumptions (Mezirow, 1997).

Putting TLT into practice involves strategically engaging students in learning activities that encourage students to (1) acknowledge their unique point of view and (2) reflect upon their assumptions in critical discourse. The incorporation of debates, either in small groups or with the entire class, are a commonly suggested strategy to encourage critical analysis and reflection. Similarly, self-reflection can be elicited using role-playing or simulations, either within or outside of the classroom (e.g., field trips, community-based projects) (Cranton, 2000). A critical component of these sorts of transformative activities is follow-up reflection, which can occur in the form of journaling, group discussion/debrief, or position papers.

The role of the educator in this endeavor is both pivotal and multi-faceted. First and foremost, the educator is responsible for creating a classroom environment — whether physical or virtual — in which students are comfortable recognizing and challenging their frames of reference (Brookfield, 1995; Taylor, 1998). Educators of adult learners must also be prepared to address the dissonance (or conflict) that emerges from confronting student conceptions (Saavedra, 1996; Taylor, 1998). Providing constructive feedback and guidance to adult learners requires an instructor who is not only "trusting, empathetic, caring, authentic, [and] sincere" but, further, acts as a "learning companion" to adult students in their process of transformation (Cranton \& Wright, 2008; Taylor, 1998).

In order to address the disconnect we identified in our students' conceptions, then, we should consider modifying our classroom environment to be more conducive to transformative learning. As previously mentioned, the course under discussion is a core requirement of the program, which-to an extent-inhibits the flexibility with which it is structured. Within the program, core courses are required to address certain requisite competencies. That being said, there is a great deal of freedom afforded to faculty in terms of how those competencies are achieved. Encouraging students to pursue analytic assignments relevant to their career paths could be a means of encouraging the autonomy necessary to elicit transformative learning. TLT could also be applied through the restructuring of classroom interactions to be more challenging of student assumptions, prompting critical discourse on the meaning and significance of course content. The efforts made in this manuscript to better understand pre-existing student conceptions of course materials, although informative, should only be taken at face value for what they are: a first step in the direction of self-directed learning. Future application of these findings should be incorporated into the ongoing process of improving the educational methods used in our program to better reach its students.

\section{Conclusions}

Our data suggest that student conceptions of environment upon entering our Master of Public Health degree are partial, and lack a systems perspective on the interconnectedness of human activity, environmental states, and population health. Of course, arriving with an incomplete understanding of the subject matter is expected; students are not expected to fully comprehend the depth/scope of EHS on the first day of class. The extent to which students stay "locked in" to their pre-semester conceptions of course topics, however, may impede their motivation, engagement, and perceived significance of the subject matter in the larger scope of public health practice. Modifying these

Journal of the Scholarship of Teaching and Learning, Vol. 19, No. 3, June 2019. josotl.indiana.edu 
conceptions is a key educational need for future practitioners whose aim is the prevention of unwanted health states related to the environments groups of people occupy. Transformative Learning Theory may provide an appropriate framework for modifying student conceptions of environment as they relate to public health.

\section{Acknowledgements}

The authors are grateful to Marie Kellemen for early brainstorming, research assistance and data collection which aided in the development of this study.

\section{References}

American Public Health Association (APHA). (2017). 10 Essential Public Health Services. Retrieved from https://apha.org/about-apha/centers-and-programs/quality-improvement-initiatives/10essential-public-health-services

Atkinson, J. W., \& Feather, N. T. (1966). A Theory of Achievement Motivation (Vol. 66). Wiley New York.

Ames, C., \& Archer, J. (1988). Achievement goals in the classroom: Students' learning strategies and motivation processes. Journal of Educational Psychology, 80(3), 260-267. https://doi.org/10.1037/0022-0663.80.3.260

Archer, J. (1994). Achievement goals as a measure of motivation in university students. Contemporary Educational Psychology, 19(4), 430-446. https://doi.org/10.1006/ceps.1994.1031

Brookfield, S. D. (1995). Becoming a Critically Reflective Teacher (1st edition). San Francisco: Jossey-Bass.

Carre, P. (2000). Motivation in adult education: from engagement to performance. Paper presented at the $41^{\text {st }}$ Adult Education Research Conference. Vancouver, Canada.

Cranton, P. (2000). Individual differences and transformative learning. Learning as Transformation: Critical Perspectives on a Theory in Progress, 181-204.

Cranton, P., \& Wright, B. (2008). The transformative educator as learning companion, the transformative educator as learning companion. Journal of Transformative Education, 6(1), 33-47. https://doi.org/10.1177/1541344608316961

Dweck, C. S. (1986). Motivational processes affecting learning. American Psychologist, 41(10), 10401048. https://doi.org/10.1037/0003-066X.41.10.1040

Griffiths, A. K., Thomey, K., Cooke, B., \& Normore, G. (1988). Remediation of student-specific misconceptions relating to three science concepts. Journal of Research in Science Teaching, 25(9), 709-719. https://doi.org/10.1002/tea.3660250902

Hegarty, N. (2011). Adult learners as graduate students: Underlying motivation in completing graduate programs. The Journal of Continuing Higher Education, 59(3), 146-151. https://doi.org/10.1080/07377363.2011.614883 
Knowles, M. (1973). The Adult Learner: A Neglected Species. Houston, TX: Gulf Publishing Company.

Knowles, M. S. (1984). Andragogy in Action: Applying Modern Principles of Adult Learning. Wiley.

Knowles, M. S., Holton, E. F., \& Swanson, R. A. (2015). The Adult Learner: The definitive classic in adult education and human resource development. New York, NY: Routledge.

Mezirow, J. (1997). Transformative learning: Theory to practice. New Directions for Adult and Continuing Education, 1997(74), 5-12. https://doi.org/10.1002/ace.7401

Mezirow, J., \& Taylor, E. W. (2009). Transformative Learning in Practice: Insights from Community, Workplace, and Higher Education (1st ed). San Francisco, CA: Jossey-Bass.

Miles, M. B., Huberman, A. M., \& Saldana, J. (2014). Qualitative data analysis: A method sourcebook. CA, US: Sage Publications.

Rothes, A., Lemos, M. S., \& Gonçalves, T. (2014). Motives and beliefs of learners enrolled in adult education. International Conference on Education \& Educational Psychology 2013 (ICEEPSY 2013), 112, 939-948. https://doi.org/10.1016/j.sbspro.2014.01.1252

Saavedra, E. (1996). Teachers study groups: Contexts for transformative learning and action. Theory into Practice, 35(4), 271-277.

Taylor, E. W. (1998). The Theory and Practice of Transformative Learning: A Critical Review. Information Series No. 374. Center on Education and Training for Employment, Columbus, OH. Retrieved from https://eric.ed.gov/?id=ED423422

Thomas, D. R. (2006). A general inductive approach for analyzing qualitative evaluation data. American Journal of Evaluation, 27(2), 237-246.

World Health Organization (WHO) Regional Office for Europe. (2017). Public Health Services. Retrieved from http://www.euro.who.int/en/health-topics/Health-systems/public-healthservices/public-health-services

Zoller, U. (1996). The use of examinations for revealing and distinguishing between students' misconceptions, misunderstandings and "no conceptions" in college chemistry. Research in Science Education, 26(3), 317-326. https://doi.org/10.1007/BF02356942 